Article

\title{
Structured Collaboration Across a Transformative Knowledge Network-Learning Across Disciplines, Cultures and Contexts?
}

\author{
Adrian Ely ${ }^{1, *(1)}$, Anabel Marin ${ }^{2}$, Lakshmi Charli-Joseph ${ }^{3}\left(\mathbb{D}\right.$, Dinesh Abrol ${ }^{4}$, Marina Apgar ${ }^{5}$, \\ Joanes Atela ${ }^{6}$, Becky Ayre ${ }^{5}$, Robert Byrne ${ }^{1}$, Bikramaditya K. Choudhary ${ }^{4} \mathbb{C}$, Victoria Chengo ${ }^{6}$, \\ Almendra Cremaschi ${ }^{2}$, Rowan Davis ${ }^{5}$ (i), Pranav Desai ${ }^{4}$, Hallie Eakin ${ }^{7}$, Pravin Kushwaha ${ }^{4}$, \\ Fiona Marshall ${ }^{1}$, Kennedy Mbeva ${ }^{6}$, Nora Ndege ${ }^{6}$, Cosmas Ochieng ${ }^{8}$, David Ockwell ${ }^{9}$, \\ Per Olsson ${ }^{10}{ }^{(}$, Nathan Oxley ${ }^{5}$, Laura Pereira ${ }^{11}{ }^{\circ}$, Ritu Priya ${ }^{4}{ }^{(}$, Aschalew Tigabu ${ }^{6}(\mathbb{D}$, \\ Patrick Van Zwanenberg ${ }^{2}$ and Lichao Yang ${ }^{12}$ \\ 1 SPRU—Science Policy Research Unit/STEPS Centre, University of Sussex, Brighton BN1 9SL, UK; \\ r.p.byrne@sussex.ac.uk (R.B.); f.marshall@sussex.ac.uk (F.M.) \\ 2 Centro de Investigaciones para la Transformación, Universidad Nacional de San Martín, \\ 1650 San Martín, Buenos Aires Province, Argentina; amarin@unsam.edu.ar (A.M.); \\ acremaschi@unsam.edu.ar (A.C.); pvanzwanenberg@unsam.edu.ar (P.V.Z.) \\ 3 Laboratorio Nacional de Ciencias de la Sostenibilidad (LANCIS), Instituto de Ecología, Universidad \\ Nacional Autónoma de México, 06320 Ciudad de Mexico, Mexico; lakshmi.charli@iecologia.unam.mx \\ 4 TRCSS, JNU-Transdisciplinary Research Cluster on Sustainability Studies, Jawaharlal Nehru University, \\ New Delhi 110067, India; dinesh.abrol@gmail.com (D.A.); bkcjnu@gmail.com (B.K.C.); \\ dpranav@hotmail.com (P.D.); pravin.kushwaha@gmail.com (P.K.); ritupriyajnu@gmail.com (R.P.) \\ 5 Institute of Development Studies/STEPS Centre, University of Sussex, Falmer, Brighton BN1 9RH, UK; \\ m.apgar@ids.ac.uk (M.A.); b.ayre@ids.ac.uk (R.A.); rowanD017@hotmail.com (R.D.); \\ n.oxley@ids.ac.uk (N.O.) \\ 6 African Centre for Technology Studies (ACTS) ICIPE, Duduville Campus, Kasarani 00608, Nairobi, Kenya; \\ j.atela@acts-net.org (J.A.); v.chengo@acts-net.org (V.C.); k.mbeva@acts-net.org (K.M.); \\ n.ndege@acts-net.org (N.N.); a.tigabu@acts-net.org (A.T.) \\ 7 School of Sustainability, Arizona State University, Tempe, AZ 85287-5502, USA; hallie.eakin@asu.edu \\ 8 African Development Bank, 1387 Abidjan 01, Cote D'Ivoire; c.ochieng@afdb.org \\ 9 School of Global Studies/STEPS Centre, University of Sussex, Brighton BN1 9RH, UK; \\ d.ockwell@sussex.ac.uk \\ 10 Stockholm Resilience Centre, Stockholm University, 11351 Stockholm, Sweden; per.olsson@su.se \\ 11 Centre for Food Policy, City University of London, London WC2N 5DU, UK; pereira.laura18@gmail.com \\ 12 School of Social Development and Public Policy, Beijing Normal University, Beijing 100000, China; \\ yanglichao@bnu.edu.cn \\ * Correspondence: a.v.ely@sussex.ac.uk; Tel.: +44-(0)1273-873-026
}

Received: 5 February 2020; Accepted: 19 March 2020; Published: 24 March 2020

Abstract: Realising the Sustainable Development Goals (SDGs) will require transformative changes at micro, meso and macro levels and across diverse geographies. Collaborative, transdisciplinary research has a role to play in documenting, understanding and contributing to such transformations. Previous work has investigated the role of this research in Europe and North America, however the dynamics of transdisciplinary research on 'transformations to sustainability' in other parts of the world are less well-understood. This paper reports on an international project that involved transdisciplinary research in six different hubs across the globe and was strategically designed to enable mutual learning and exchange. It draws on surveys, reports and research outputs to analyse the processes of transdisciplinary collaboration for sustainability that took place between 2015-2019. The paper illustrates how the project was structured in order to enable learning across disciplines, cultures and contexts and describes how it also provided for the negotiation of epistemological frameworks and different normative commitments between members across the network. To this 
end, it discusses lessons regarding the use of theoretical and methodological anchors, multi-loop learning and evaluating emergent change (including the difficulties encountered). It offers insights for the design and implementation of future international transdisciplinary collaborations that address locally-specific sustainability challenges within the universal framework of the 2030 Agenda for Sustainable Development.

Keywords: pathways; transdisciplinary research; international collaboration; sustainable development goals; theory of change; transformation; sustainable development goals

\section{Introduction and Background}

The Sustainable Development Goals (SDGs), which grew out of the Rio+20 UN Summit in Rio de Janeiro in 2012 and were agreed at the UN General Assembly in 2015, represent the most ambitious and internationally-recognised agenda for sustainability that the world has seen. In comparison to their forerunners the Millennium Development Goals (MDGs), the global goals are 'universal' in that they apply to all countries. Their pledge to "leave no-one behind" [1] requires attention to the most marginalised communities and points to the need to address power and structural inequalities.

In contrast to the 'universal' nature of the 17 goals and 169 targets agreed in New York in 2015 lie the radically different contexts-at national and subnational levels-in which these ambitions are to be realised. There is a clear need for collaborative research that addresses the challenge of translating global goals to local action and a further need for the international community to learn from these processes of collaboration.

Networked transdisciplinary research bringing together scholars from different disciplines and non-academic partners is increasingly looked to as a response to this "2030 Agenda" around partnerships for the goals [2], with national governments dedicating resources to international collaborative programmes of this type (e.g., through platforms such as 'Future Earth' [3]). And yet the majority of transdisciplinary research and its explicit theorisation, has taken place in a limited set of (primarily advanced economy) contexts. If it is to respond to a universal agenda, transdisciplinary research will need to involve types of collaboration that play out differently within localities that possess their own specific histories, cultures and dynamics. A better understanding of how to develop modes of collaboration that respect and take advantage of differences across contexts can inform future networked, transdisciplinary research efforts for sustainability.

The 'Pathways' Transformative Knowledge Network (TKN) is an international group of research organisations, collaborating to explore processes of social transformation and to share insights. Between 2015-2019, the TKN explored different approaches to transdisciplinary research-experimenting, documenting and comparing across the hubs in the network with the objective of "learning across disciplines, cultures and contexts" [4]. The project is one of the three initial transformative knowledge networks funded under the Future Earth 'Transformations to Sustainability' programme.

This paper provides an initial analysis of the project activities, experiences and insights, drawing from the different contexts of implementation. In particular, it discusses the structure and design of the project and the elements that enabled (or constrained) collaboration and learning across the network's six hubs (in Mexico, Argentina, Kenya, India, China and the United Kingdom (UK)) each with their own disciplinary traditions and histories of engaged research. The paper argues that the project benefited from the use of theoretical and methodological anchors that provided a shared language for the negotiation of different epistemological frameworks and normative commitments. It further identifies some of the challenges to this cross-learning process, including the flexibility required to accommodate very different approaches and the limits to comparative analysis.

The analysis is instructive for future collaborative, networked social science projects that aim to contribute to the analysis and enactment of social transformations to sustainability. 


\section{Transdisciplinary Research and Transformations to Sustainability}

\subsection{Insights from the Literature}

Working across more than one scientific discipline in parallel (multidisciplinarity) and in combination (interdisciplinarity) has long been recognised as a feature of problem-oriented research [5], in particular applied to the challenges of sustainability [6]. All of the regions hosting hubs of the 'Pathways' TKN have their own histories of transdisciplinary research-the production of knowledge and action through collaborations between research and non-research communities. However, the explicit adoption of the terminology of "transdisciplinary" research by the sustainability transformations community has been relatively recent [7-10].

Considering transdisciplinary research as a component of sustainability science, Brandt et al. [11] investigate the process phases, knowledge types and the intensity of involvement of practitioners displayed by 236 peer-reviewed transdisciplinary papers. Drawing on earlier work, they argue that there are three process phases of transdisciplinary research: 1) problem identification, 2) problem analysis and 3) integration and application; and that there are three knowledge types that must be integrated in such research: system knowledge, target knowledge and transformation knowledge. The findings of their review are presented in relation to five pre-identified challenges in Table 1 below. Brandt et al. [11] illustrated that transdisciplinary research was increasingly being referred to as an approach to sustainability challenges, however terminology was yet to stabilize and there were clearly limitations in the applicability of "concepts such as process phases and knowledge types" if practitioners and scientists seeking to engage in concrete transdisciplinary research could not understand them. Conceptual papers were found to be abundant in transdisciplinary work but (as mentioned also in more recent work-see Reference [12]) there remains terminological ambiguity and the development of concepts/typologies is perhaps outpacing their application in practical empirical transdisciplinary research. In terms of methods, the review found that these differed with the ontological approach of the researchers and thus-in opposition to calls for a "reproducible and transparent methodological framework for transdisciplinary research" - the researchers argued that "seemingly objective selection of methods can be expected to be unavoidably subjectively biased." This can be expected to be especially true when methods are applied across different contexts in response to different challenges. Finally, the authors found that generating transdisciplinary research with high-scientific impact remains challenging - a point to which we return in the conclusion.

Table 1. Challenges of transdisciplinary research in sustainability science (derived from review by Reference [11]).

\begin{tabular}{cc}
$\begin{array}{c}\text { Challenge to Undertaking Transdisciplinary } \\
\text { Approaches to Sustainability Science }\end{array}$ & Finding of Review [11] \\
\hline Coherent Framing & $\begin{array}{c}\text { Transdisciplinary research in sustainability science is } \\
\text { increasing but under diverse terms }\end{array}$ \\
\hline Integration of Methods & $\begin{array}{c}\text { Method sets used are independent of process phases and } \\
\text { knowledge types }\end{array}$ \\
Research Process and Knowledge Production. & $\begin{array}{c}\text { There is a gap between 'best practice' transdisciplinary } \\
\text { research as advocated and transdisciplinary research as } \\
\text { published in scientific journals }\end{array}$ \\
\hline Practitioners' Engagement & $\begin{array}{c}\text { Knowledge is interchanged, yet empowerment is rare } \\
\text { Generating transdisciplinary research with high-scientific } \\
\text { impact remains challenging }\end{array}$ \\
\hline
\end{tabular}

The changing nature of inter/cross/transdisciplinary work and an appreciation of the key contours of debate in the field, has continued to develop over the past decade [12]. Other work, whilst not using the "transdisciplinary" moniker has described interactions between researchers and other societal 
groups. Along with 'co-design' and 'co-dissemination,' the term "co-production," for example, has assumed an important role in recent research in transformations to sustainability [10,13]). Miller and Wyborn [14] review the history and theory around co-production from a broad set of disciplines and fields (including public and business administration, science and technology studies and sustainability science), arguing that some convergence is visible across traditions but that some contemporary approaches [15] neglect the political insights of earlier conceptions (such as those of [16] or [17]). They argue that co-production practices should recognize and value both process and outcomes and that researchers should:

1. Be inclusive in the diversity of participants, the power accorded to them and the processes and objectives of co-production. Ensure that the institutions that enable co-production attend carefully to the credibility, legitimacy and accountability this entails.

2. Acknowledge that co-production is a process of reconfiguring science and its social authority. Such processes require participants to be reflexive about the inherently political nature of producing knowledge in the service of changing social order at local to global scales.

3. Recognize that public engagement, deliberation and debate will shape the content and relevance of knowledge and its ability to help construct and empower institutions to "facilitate sustainability" [14]

These are particularly challenging when transdisciplinary research comes under institutional pressures of knowledge commodification [18] or when modernist socio-technical practices including research neglect other-than-modern alternatives [19].

\subsection{The Pathways Network's Approach}

Attention to these and other considerations in the research process (with or without adopting the formal 'process phases' of Hadorn et al. [8] or other transdisciplinary scholars) was a characteristic of the 'Pathways' network. However, the different disciplinary, institutional and socio-cultural contexts in which the research was conducted required that-rather than attempting to roll out universal guidelines-the teams explored their practical applicability in each hub. The approach adopted in this regard was the "transformation laboratory" or T-Lab, discussed in greater detail below and defined as a process involving research and transdisciplinary engagement to address complex social-ecological problems or challenges $[20,21]$. The Pathways Network recognized that the extent to which science can be reconfigured is political and differently constrained in the different geographies where the T-Labs were implemented. Further, what defines credible, legitimate and salient work would necessarily vary across the network as the teams responded to the specific ecological-political-social moments that circumscribed the work in each hub.

Transdisciplinary engagement with diverse partners in each of the hubs started with the process of co-design [22], which took the form of multi-stakeholder workshops in each of the six hubs of the network. These (and the initial transdisciplinary research designs that emerged from them) responded to locally-identified sustainability challenges, organized around three broad themes and involved networks selected by the teams from each of the six hub organisations listed below:

Theme 1-Sustainable agricultural and food systems for healthy livelihoods

- $\quad$ The future of seeds (and agriculture) in Argentina/South America hub-Centre for Research on Transformation (CENIT), Buenos Aires, Argentina

- Transformations to sustainable food systems in Brighton and Hove/Europe hub-STEPS Centre, University of Sussex, UK and Stockholm Resilience Centre, Sweden

Theme 2-Low carbon energy transitions

- Low carbon energy transitions that meet the needs of the poor/Africa Sustainability Hub-African Centre for Technology Studies, Nairobi, Kenya 
- China's green transformations/China Hub-Beijing Normal University School of Social Development and Public Policy, China

Theme 3-Water and waste for sustainable cities

- The urban system of water and waste management in Gurgaon, India/South Asia hub-Transdisciplinary Research Cluster on Sustainability Studies, Jawaharlal Nehru University, New Delhi India

- Water governance challenges, Mexico City/North America hub-Arizona State University, USA and National Autonomous University of Mexico, Mexico

As discussed further below, the themes acted as a means to group hubs into pairs in the hope of providing opportunities to share lessons across related sustainability challenges in distinct contexts. These themes were just one element of the design of the network, strategically structured to foster co-learning and exchange. The next section describes other various elements of this design in more detail.

\section{Structured Design to Allow for Co-Learning and Exchange}

The project was designed to provide flexibility for location-specific decisions about transdisciplinary research and engagement (including methods, discussed later in 4.2 and Table 4 below), thus allowing reflection within each individual hub around how to improve transdisciplinary practice. Table 2 provides a chronological outline of the various milestones in the project, starting from co-design workshops, including PIPAs (Participatory Impact Pathways Analysis) and T-Labs (both described below) as well as moments for reflection. From an organizational learning perspective [23] this provided opportunities for single-loop learning (instrumental learning through theoretically-informed action) and double-loop learning (questioning the values underlying theories in order to improve them). For example, in each hub there was a process of learning about what activities or approaches were effective or not as the projects unfolded in each locale (single loop learning). As described below, there was also more substantive, reflective learning in hubs concerning how problems were framed and what this implied for solution pathways (double-loop learning). The project was also designed to foster triple-loop learning, particularly through cross-hub interaction, (learning about the learning process, with the hope of learning how to learn better), so that these insights could inform future networked transdisciplinary research projects.

With this in mind, beyond the independently coherent hub-based work, the project allowed for the collection of standardised data at symmetrical points across all hubs, in an attempt to compare and learn across contexts. As such, the transdisciplinary research process in each hub was integrated into the design of the project and punctuated by moments for data collection, sharing and co-learning and collaborative reflection (see Table 2).

At the inception workshop in April 2016, the representatives of each hub team undertook an adapted PIPA process (see below) to map out the stakeholders that would be engaged during the course of their transdisciplinary research. Results of each of these hub-specific processes were included in the inception workshop report, which established the methodologies for subsequent data collection across all hubs. These methods were surveys (collecting qualitative data) and structured reporting on T-labs (including qualitative data on process and quantitative data on stakeholder participation).

The project conducted three internal surveys (baseline, mid-point and final, indicated in italics in Table 2) in which members of each of the hub teams were asked similar questions regarding their research process. In each case, standardised questions allowed the collection of qualitative data that could aid comparative analysis and reflection. 
Table 2. Key moments in the organisation of the 'Pathways' Transformative Knowledge Network (TKN) and collaborative developments that these enabled.

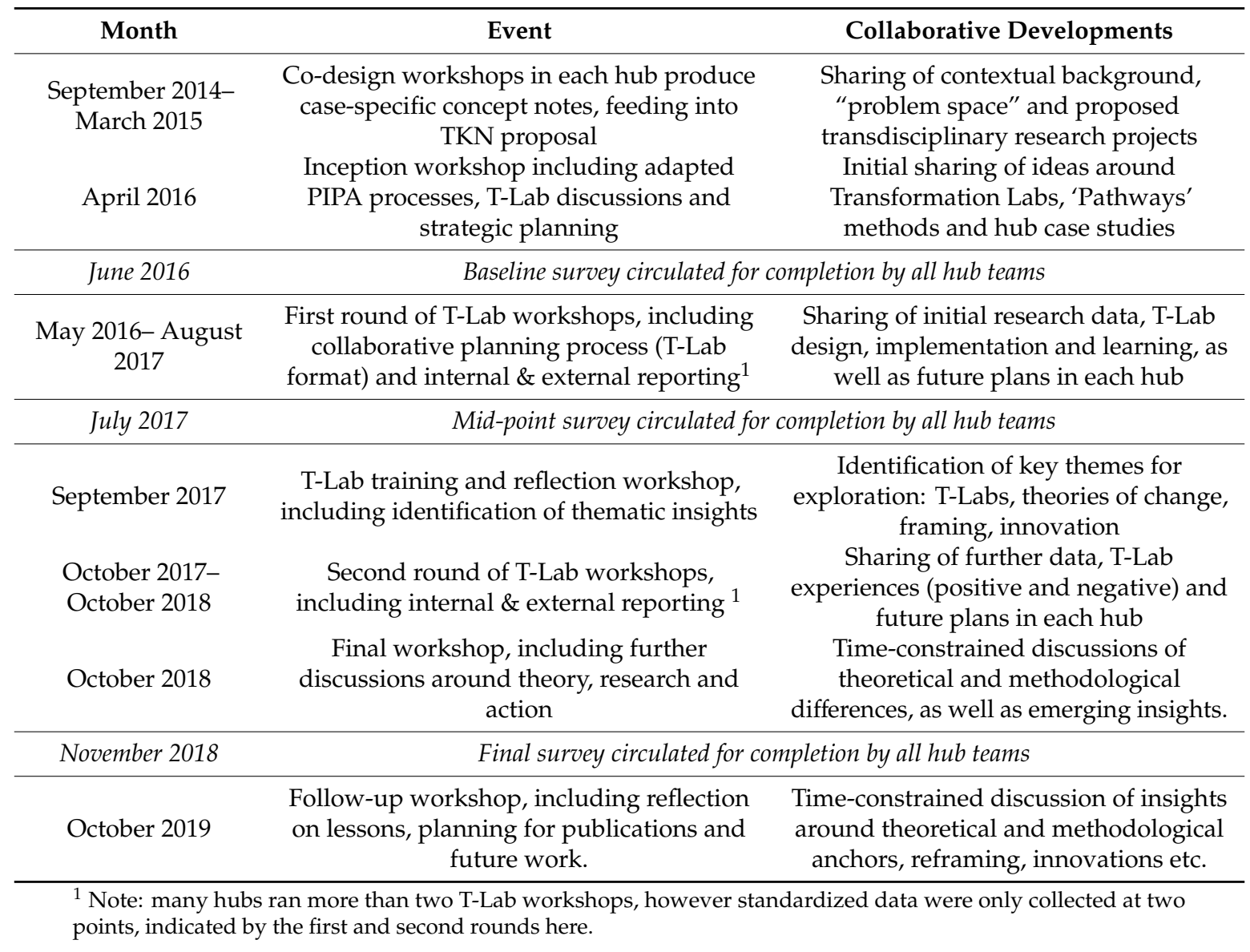

Structured reporting by each hub took place after each of the two T-Lab workshops (specific events in each hub that were used for data collection). Hubs were invited to produce internal reports for circulation around the network, which were similarly structured to include questions on decisions taken, methods used, changes observed, findings made and lessons learned. They also reported on the participation of stakeholders across academic and non-academic groups in each hub. This method adopted the funder's pre-determined categories of stakeholders (defined at the outset of the project in formal reporting requirements): academia, research body, think tank, NGO, public administration, civil society, other. We found that these were insufficient in their specificity, so in some cases hubs added sub-categories that catered to their own situation but direct comparison between the hubs was only possible on the basis of the original categories. In each case, beyond the category of stakeholder, we made subjective assessments of their degree of power (power over the transformation) and their degree of alignment with our own framing of the sustainability challenge. This comparative method offered a way to begin to understand the hubs' different approaches to transdisciplinary research and to consider how these related to the disciplines, cultures and contexts that were prevalent in each of the hubs.

Several features of the TKN's design were further aimed at fostering collaboration between countries in the global North and global South in order to enable learning from diverse contexts. These are outlined below.

Paired hubs-from the outset of the project, hubs were paired on the basis of shared domains of work, as described above. This pairing was used at various points through the project in order to encourage participants to share their rationales for particular decisions around research and engagement (e.g., exchanging T-Lab designs in a specific format prior to the first T-Lab workshop), their experiences 
(e.g., of positive and negative aspects of T-Labs) and lessons (e.g., relating to the specific domains in which they were working). Nevertheless, the process of co-design and the inevitable consequences of problem reframing that often occurs in co-design processes, made the initial thematic structure of the paired hubs less salient than other, less visible points of comparison such as approaches used in engagement or the scale or goals of implementation.

T-Lab design formats-in advance of the first round of T-Lab workshops, hubs were invited to exchange their proposed designs in a standard form in order to seek inputs or comments from their paired hub.

Exchanges-incorporated within the design of the project (including in the budget of each hub) were a series of exchange visits that would enable researchers from paired hubs to undertake collaborative research through planning, writing or sharing insights from their T-Labs. These were used to aid project planning, collaborative writing (see 'cross-learning blogs' below) and planning future work and funding proposals. They were particularly targeted at early career researchers.

Co-learning blogs-co-learning blogs were incorporated into the design of the project as a prompt to paired hubs to think together and produce collaborative work. These offered the opportunity for collaborative writing without the constraints that more formal demands (e.g., co-authored journal articles) necessarily involve, for example, the identification of a shared theoretical framework. All in all, seven blogs were published involving co-authors from two or more hubs.

Taken together, this approach to the design of the project and the various processes for data collection and sharing described above provided the basis for a uniquely international exploration of the role of transdisciplinary social science in transformations to sustainability. We next discuss the trade-offs between this structured approach and the flexibility required in a diverse international network, before going on to explore the insights that this structured approach has begun to provide for transdisciplinary collaboration for sustainability.

\section{Anchors as a Focus for Cross-Learning and Negotiation}

The 'Pathways' transformative knowledge network was co-led from institutions in the UK and Argentina, with researchers from each hub playing a key role in project design, coordination, management and execution. From the perspective of the co-leads and the consortium more generally, however [24], local co-design and ownership was seen as a prerequisite to effective transdisciplinary research. Whilst the standardization of elements of the hub activities and of data (see above) was attractive from the perspective of a pseudo-experimental comparative study of transdisciplinary work, the unique characteristics of the hubs, the personnel within the hub teams and the contexts in which they were embedded meant that it was unrealistic to control variables such as methods or epistemological frameworks in any experimentally meaningful way. While creating a coherent organizational structure for the network was clearly necessary to acquire funding and initiate the international initiative, it was difficult to anticipate what would be the appropriate methods or approaches for each context and how the particular problem domains would be reframed, what local collaborators would be involved and what opportunities for action and change would materialize once the projects were initiated. Indeed, a key ambition of the project was to explore how the very different historical and contemporary characteristics of the hubs led to transdisciplinary processes that varied in these and other dimensions. The challenge for the network then was to provide a structured process of reflection such that the decisions on process, method or approach made within each hub could be documented and compared, if not in real-time, at a moment when the hub teams could pause for reflection. This challenge is common to projects taking a complexity-aware approach, recognising emergence, while working within institutional and funding parameters that push towards pre-defined and linear planning. A compromise involved adopting 'anchors' that provided a common language and methodological approach, without constraining the creativity and freedom of hubs to carry out the work that they saw as worthwhile and potentially impactful, within their chosen theoretical and epistemological traditions. In a sense, these 'anchors' allowed the T-Lab concept to serve as a boundary object [25]. Each T-Lab 
shared common elements, to which the hub participants could ascribe similar meanings, such that the T-Lab concept could serve as a shared concept and approach despite differences in implementation.

\subsection{Theoretical Anchors}

The 'Pathways' TKN is made up of a group of organisations and individuals from diverse disciplinary backgrounds (see above). Numerous interlinking bilateral relationships and memberships of international networks (Globelics, Resilience Alliance) combined with a relatively high level of political alignment across the network. This did not necessarily translate into a history of working with any particular theoretical framework. However, all hubs had-at different points and to varying extents - collaborated with members of the STEPS Centre at the University of Sussex, UK. These collaborations have taken place around topics such as technology regulation [26], grassroots innovation [27], discussions of resilience [28] or-more generally—political engagement [29,30], all of which drew upon the pathways approach first articulated in Leach et al. [31]. This history provided us with a number of theoretical "anchors" that could be applied differently in each case:

- Systems-"particular configurations of dynamic interacting social, technological and environmental elements" [31]. The focus on systemic transformation underpinned the design of the project. This included a definition of the system (including explicit attention to how the system was framed) in the original co-design phase and a consideration of how the system needed to change to overcome the sustainability problem that motivated the research.

- Framings - "the different ways of understanding or representing a social, technological or natural system and its relevant environment. Among other aspects, this includes the ways system elements are bounded, characterized and prioritized and meanings and normative values attached to each" [31]. Building on Goffman's [32] seminal work, the notion of framing has a long history in policy studies [33-35] and has been incorporated into the pathways approach. The co-design workshops and concept notes that emerged from them recognised different system framings and their fundamental link to debates and challenges associated with sustainability. Whilst notions of "reframing" such debates have been applied to the pathways approach in previous studies (see References [36,37]), the current project offered significant opportunities to develop this area of thinking.

- Pathways - "the particular directions in which interacting social, technological and environmental systems co-evolve over time" [31]. The concept notes that had emerged from co-design workshops identified dominant and alternative pathways but adopted different lenses through which these were characterised in each context. At the same time, the pathways approach (and the notion of pathways) played a different role (and a more-or-less important role) in each case. Some hubs conceived of pathways as open-ended, with the T-Lab process relatively agnostic to the ultimate direction pursued as long as it emerged from the empowerment of participants and their normative sustainability goals (North America hub, European hub). In other cases, the ambition was to alter current dominant trajectories by introducing a specific, compelling alternative technological and institutional pathway (Latin America hub). In the South Asia Hub, the approach was to challenge the regime of neo-liberal urban planning and governance and form a collective agency of the mobilised publics to promote the coproduction of knowledge and co-design of alternative solutions. In some cases (e.g., China hub) gender played a more central role to the work, whilst others (Africa hub) engaged more with issues of poverty and environmental sustainability. Taken together, these approaches to innovating around the notion of 'pathways' offered potential insights into transformative pathways to sustainability.

Whilst acting as anchors, these concepts were offered as heuristic starting points rather than a rigid theoretical framework. The rationale was that there was at least some familiarity with them across each of the hubs and thus they could act as a lingua franca through which more abstract theoretical notions could be explored. The role of the project was not to test these concepts (derived from work 
led from the global North) for their applicability in different contexts but to explore their limitations and put forward alternatives grounded in the contexts in which the research was conducted.

\subsection{Methodological Anchors}

As discussed in previous work on transdisciplinary research [11] and mentioned above, the TKN decided against specifying that the same methods should be used across all hubs (which were working across different contexts in response to different challenges). Instead, we adopted the overall approach of 'T-Labs,' around which different hubs could experiment with different methods for research and engagement. T-Labs (shorthand for Transformations laboratories) were first experimented with in the run-up to the Transformations 2015 conference hosted by Stockholm Resilience Centre and are one of the panoply of strategic approaches to enable or unleash systemic change through experimentation [38,39] in 'labs' [21]. Other concepts include transition labs [40], social labs [41], social innovation labs [42], living labs [43,44] or real-world labs [45]. Rather than being framed as contributions to a managed transition to a well-characterised future system, transformation labs focus on human-nature interactions and are seen as part of open-ended processes that fit situations with high uncertainty-strategically facilitated to allow for emergence and strengthen capacities for navigating complex transformative processes.

Like the theoretical concepts above, the notion of T-Labs acted as an anchor to be negotiated and experimented with, rather than methodological tool or protocol to be implemented in a standard manner across the world. Indeed, some hubs chose not to use the term in practice due to local sensitivities, whilst still sharing experiences and adopting the anchor term in discussions within the network.

\section{Results, Findings and Emerging Insights}

\subsection{Accommodating Theoretical Diversity}

Whilst at least one of the anchors around 'systems', 'pathways' and 'framings' was used by each of the hubs, their theoretical conceptions of transformation differed. This translated into sometimes irreconcilable divergences in epistemological views, which combined with different normative commitments around the appropriate role of researchers in studying or intervening in systems (see below). In most cases, these theories of transformation could be explicitly compared with a view to negotiating differences and understanding the logic behind the selection of different methods (see below). Beyond theories of transformation (see Table 3), discussions about the theory of change involving adapted participatory impact pathways analysis (PIPA—see References [46,47]) and diagrammatic methods describing the strategies adopted by each hub were used. However, whilst attempts were made in regard both to theoretical alignment and the induction of an overarching complexity-aware theory of change, constraints around resources and in particular the time available for in-depth reflection and discussion have so far stifled these efforts. The ambition of achieving multiple levels of "loop learning" simultaneously is challenging in a relatively compressed time-frame. Each T-Lab was designed to facilitate single-loop and double-loop learning in relation to the specific problem contexts each was addressing; simultaneous externally oriented learning across the hubs about the process of the T-Lab and the learning itself is perhaps only now, through collaborative writing exercises such as this manuscript production, occurring.

There were instances of collective theorizing across this diversity. Some of the lessons that emerged from the network activities contributed to the delineation of "systemic" and "structural" approaches to transformations research [48]. For example, the South Asia hub attempted structural change from a neoliberal, private sector-led and state-facilitated development pathway to a more inclusive counter-hegemonic mobilization for more inclusive planning for urban water and waste systems (through cross-class alliances of mobilized publics), while the effort in the South American hub to create a legal and institutional alternative to commercial seed breeding could also be interpreted 
as an effort in structural change. Other activities focused more on what have since been characterized as "enabling" approaches that "highlight the agency and uncertainties inherent in choosing aims and directions for transformative change" [48]. For example, in the China hub, the effort was to open avenues for new policy by creating spaces to share perspectives that had never been voiced; in the North American hub, participatory activities were implemented to build bridges across divides of livelihood, identity and values in order to foster collective action.

Table 3. Objectives and underlying theories of transformation from TKN hubs.

\begin{tabular}{|c|c|c|}
\hline Hub & General Objective of Project/Case Study & $\begin{array}{l}\text { Underlying Theories of Transformation } \\
\text { That Inform the Choice of Method }\end{array}$ \\
\hline $\begin{array}{l}\text { North America } \\
\text { Hub } \\
\text { (Mexico) }\end{array}$ & $\begin{array}{l}\text { To design and implement a process known } \\
\text { as "transformation laboratories" with the } \\
\text { aim of identifying, mobilizing and } \\
\text { activating individual and collective agency } \\
\text { of actors involved in the social-ecological } \\
\text { dynamics of the Xochimilco urban wetland. }\end{array}$ & $\begin{array}{c}\text { Transformation is about bottom-up } \\
\text { building of collective agency through } \\
\text { reframing systems dynamics. } \\
\text { Transformations to sustainability (e.g., } \\
\text { [49-53]); Transformative agency (e.g., } \\
\text { [38,54]); Pathways (e.g., [25,55,56]) }\end{array}$ \\
\hline $\begin{array}{l}\text { Europe Hub } \\
\text { (UK) }\end{array}$ & $\begin{array}{l}\text { To design and implement research and } \\
\text { "transformation laboratories" with the aim } \\
\text { of enhancing the supply of local, } \\
\text { sustainably-produced food into Brighton \& } \\
\text { Hove (and drawing wider lessons for the } \\
\text { UK's agricultural transformations) }\end{array}$ & $\begin{array}{c}\text { Transformation is influenced by changing } \\
\text { cognitive, affective and political economic } \\
\text { drivers that work across individuals, } \\
\text { groups and systems. Pathways [31], politics } \\
\text { of green transformations [57], governance } \\
\text { of sustainable socio-technical transitions } \\
\text { [58], transformative pathways [4]. }\end{array}$ \\
\hline $\begin{array}{l}\text { South America } \\
\text { Hub } \\
\text { (Argentina) }\end{array}$ & $\begin{array}{l}\text { To design and implement "transformation } \\
\text { laboratories" (T-Labs) with the aim of } \\
\text { creating an experimental space in which } \\
\text { coalitions of heterogenous actors can agree } \\
\text { on a sustainability problem in the } \\
\text { agricultural seed sector and develop and } \\
\text { prototype possible solutions }\end{array}$ & $\begin{array}{l}\text { Transformation involves experimentation } \\
\text { with novel, more sustainable socio-technical } \\
\text { practices and the development of } \\
\text { alternative 'path breaking' socio-technical } \\
\text { configurations }[59,60] \text {. }\end{array}$ \\
\hline $\begin{array}{l}\text { Africa Hub } \\
\text { (Kenya) }\end{array}$ & $\begin{array}{l}\text { To use the T-Lab approach to explore how } \\
\text { Kenya can enable sustainable and equitable } \\
\text { access to solar home systems for all via } \\
\text { mobile-based payment systems, especially } \\
\text { those who cannot participate in } \\
\text { micro-financing schemes [61]. }\end{array}$ & $\begin{array}{l}\text { The T-Lab involved different stakeholders } \\
\text { (government, NGOs, Civil society, Private } \\
\text { sector development partners, research and } \\
\text { academia) who provided rich and diverse } \\
\text { insights into what needs to be done or } \\
\text { changed to enable equitable, sustainable } \\
\text { access for all, to solar PV systems via } \\
\text { mobile-based payment systems. }\end{array}$ \\
\hline China Hub & $\begin{array}{l}\text { This study engages in the social dimensions } \\
\text { of green transformation in order to provide } \\
\text { a more holistic picture of the } \\
\text { transformations to sustainability [62]. }\end{array}$ & $\begin{array}{l}\text { Transformations in China are driven by a } \\
\text { number of actors }[63,64] \text {. The change agents } \\
\text { are different stakeholders in transformation, } \\
\text { including laid-off workers, former plant } \\
\text { owners, local government officials, scholars, } \\
\text { NGOs, etc }\end{array}$ \\
\hline $\begin{array}{l}\text { South Asia Hub } \\
\text { (India) }\end{array}$ & $\begin{array}{l}\text { To design and implement transformation } \\
\text { labs as a process with the aim of promoting } \\
\text { a collective strategy for intervention to bring } \\
\text { together the mobilised publics specifically } \\
\text { representing poor and marginalised along } \\
\text { with middle classes to develop the } \\
\text { collective practical understanding and build } \\
\text { alliances for enabling their participation in } \\
\text { planning and decision making processes of } \\
\text { water and waste water management }\end{array}$ & $\begin{array}{l}\text { Transformation is conceptualised as } \\
\text { enabling the people as a whole specifically } \\
\text { poor and marginalised to enhance their } \\
\text { access to resources and capabilities for } \\
\text { mobilisation of power to innovate and } \\
\text { foster regime change that helps to create } \\
\text { conditions for the realisation of ecologically } \\
\text { and socially just development. }\end{array}$ \\
\hline
\end{tabular}




\subsection{Methodological Differences and Normative Commitments}

The T-Lab approach provided room for significant methodological experimentation and innovation, as is evident from Table 4 below. The table only shows a small selection of the participatory methods adopted in the T-Labs. They aimed to identify and cultivate transformative pathways in contexts in which the desired end-state of the system was at least uncertain or contested, however certain normative commitments (around environmental sustainability, poverty alleviation and social justice) were shared. Under these conditions the role of T-Labs became as much about convening "transformative spaces" [65,66]-where differences could be surfaced, negotiated, tensions resolved (or otherwise) and transformative agency enhanced-whether through cognitive changes at the individual level or through fostering collaborations across individuals or groups-as about conducting research.

Different normative commitments (around the role of researchers as activists, impartial observers, experimenters) were also evident in the methods that were selected. The work in Argentina adopted a strong normative commitment to drive through change, establishing an open seed innovation platform (Bioleft, Argentina) as an example of an alternative 'path breaking' socio-technical configuration (see Table 3). The South Asia Hub focused on initiating interventions for altering the existing structures and regimes of unequal power relations by challenging neo-liberal urban planning and policy processes. Investigations in Mexico experimented by trying to build transformative agency and monitoring for subsequent transformative change, where the team is beginning to see (community-driven) results. In the UK case information was provided and diverse views exchanged but without concerted advocacy for the potential solutions that emerged. The China and Kenya hubs adopted more open-ended approaches, convening T-Lab workshops that enabled interactions between stakeholder groups that had previously remained separate. In each hub, the selection of different stakeholder types, the numbers involved (which ranged from tens to hundreds of participants) differed in accordance with the methods adopted. Alignment also differed between hubs and changed over time. Taking two hubs as exemplars, whilst the Argentinean T-Lab started with a non-aligned group of actors (at the co-design phase) and the UK work was initiated with a small, aligned group (see Reference [22]), this reversed as the Argentinean team moved towards a more activist mode around the Bioleft initiative and the UK team drew in a broader group of more powerful stakeholders to learn from and contribute to their work.

In several of the hubs, the research and engagement methods adopted served to reframe sustainability challenges through bringing marginal framings to the table. T-Labs contributed to this process by convening groups in which radically different framings of sustainability were exposed to each other (whether those represented corporate interests focusing on macro-economic development as opposed to farmer organisations focused on food sovereignty; the sustainability of land use for environmental goods rather than rental income; or the conflict in meaning and values associated with the Xochimilco wetland between illegal urban dwellers and traditional wetland agriculturalists) [67]. At the same time, it is evident from the concept notes and the subsequent project documentation that the research questions and problems identified by hubs at the outset themselves changed through the course of the project, indicating significant double-loop learning and reflection on the part of the research teams. 
Table 4. Selected participatory methods utilized in the Pathways TKN.

\begin{tabular}{|c|c|c|}
\hline Hub & Method \& Purpose/General Description & Techniques \\
\hline $\begin{array}{l}\text { North America } \\
\text { Hub (Mexico) }\end{array}$ & $\begin{array}{l}\text { Agency Network Analysis (ANA) } \\
\text { Mixed method } \\
\text { Describe the actor's agency profile by identifying individual agency } \\
\text { through collecting information about actors' social network, the } \\
\text { practices they share with the members of their social network, their } \\
\text { representation of the social ecological system and the position they } \\
\text { occupy in it. }\end{array}$ & $\begin{array}{l}\text { Ego-nets; action-nets; } \\
\text { cognitive maps }\end{array}$ \\
\hline $\begin{array}{l}\text { South Asia Hub } \\
\text { (India) }\end{array}$ & $\begin{array}{c}\text { Multi-stakeholder processes for the mobilised publics through the } \\
\text { development of their Collective Practical Understanding (CPU) } \\
\text { and actions } \\
\text { Mixed Method } \\
\text { Coproduction of knowledge, knowledge sharing, dialogues and } \\
\text { engagement with institutions of planning and governance for } \\
\text { demonstrating the possibilities of alternative pathways. } \\
\text { Development of multi-stakeholder-knowledge-sharing platform } \\
\text { enabling social mobilisation and awareness, including direct actions, } \\
\text { participation and real-world experiments. } \\
\text { Mapping of knowledge, values and institutions of mobilised publics } \\
\text { and organising them for the creation of a multi-stakeholder platform } \\
\text { for individual and collective actions. }\end{array}$ & $\begin{array}{l}\text { Transects, public meetings \& } \\
\text { focus group discussion } \\
\text { (FGD), multi-stakeholder } \\
\text { consultations, community } \\
\text { radio programmes, poster } \\
\text { exhibitions, citizens science; } \\
\text { citizens watch approaches \& } \\
\text { tools; Real world } \\
\quad \text { experiments }\end{array}$ \\
\hline $\begin{array}{l}\text { Europe Hub } \\
\text { (UK) }\end{array}$ & $\begin{array}{l}\text { Continuum' methods, specifically Evaluation } \mathbf{H} \\
\text { Qualitative method } \\
\text { Identify different actors' positions and perspectives (especially at the } \\
\text { extremes), foster discussion across them, identify challenges and } \\
\text { opportunities and work towards solutions. Gather participants } \\
\text { together to position themselves in relation to each other and to open } \\
\text { up debate. It can be effective if participants represent different sectors, } \\
\text { backgrounds or types of involvement in the issue being explored, } \\
\text { particularly if these different stakeholders do not interact often. }\end{array}$ & $\begin{array}{c}\text { Facilitated, participatory } \\
\text { workshop }\end{array}$ \\
\hline $\begin{array}{l}\text { South America } \\
\text { Hub (Argentina) }\end{array}$ & $\begin{array}{l}\text { Q Methodology } \\
\text { Mixed method } \\
\text { Identify competing discourses about the nature of sustainability } \\
\text { challenges, their drivers and their possible solutions in the seed sector } \\
\text { and map areas of consensus and disagreement between different } \\
\text { groups of stakeholders; Identify different actors' perspectives, foster } \\
\text { discussion across them, identify where alliances between different } \\
\text { actors are possible and work towards solutions. }\end{array}$ & $\begin{array}{l}\text { World café; open space } \\
\text { technology }\end{array}$ \\
\hline $\begin{array}{l}\text { Africa Hub } \\
\text { (Kenya) }\end{array}$ & $\begin{array}{l}\text { Participatory Impact Pathways Analysis (PIPA) } \\
\text { Qualitative method } \\
\text { Identification of impact pathways to detect key stakeholders with } \\
\text { interest and influence in policy, business and technology; to identify } \\
\text { the various pathways for transformation; target what pathways (i.e., } \\
\text { engagements, networks) could be engaged in the process so as to } \\
\text { enhance uptake of the research outputs. }\end{array}$ & Participatory workshop \\
\hline China Hub & $\begin{array}{l}\text { Role play simulation } \\
\text { Qualitative method }\end{array}$ & Role play \\
\hline
\end{tabular}

\subsection{Learning from Diverse Experiences with Multiple Variables}

Transdisciplinary research, like much participatory research, often builds upon existing relationships of trust between action researchers and communities, within contexts in which projects are initiated by communities themselves. From the outset of the 'Pathways' TKN it was clear that the various 
hubs were starting from very different places in terms of disciplinary and stakeholder backgrounds and networks. Whilst some had over a decade of institutional engagement with communities involved in their T-Labs, others embarked on new transdisciplinary partnerships with the project's inception. At the same time, the challenges that had been designed, the theoretical frameworks adopted by the hub teams, the normative commitments and methodological choices that were taken all added to the variables that differed across the hubs. For this reason, the scope for a natural experiment that yielded insights for overarching theories of change, clear examples of triple-loop learning or universally applicable strategies for transformative social science were limited.

Transdisciplinary work entails answers to critical knowledge-to-action questions: What needs to be done? Who needs to be involved? How can it be done? And, who can do it? These necessarily normative questions can only be answered appropriately in relation to the specific problem contexts and social/political networks accessible to each hub and are dependent on the opportunities and constraints represented by the capacities and knowledge accessible and institutional and political circumstances of each case.

Insights could potentially have been greater if the work in each of the hubs had been even more standardized (beyond adopting the anchors described above). Attempts were made at quantitative comparison of the engagement processes in each hub (see Figure 1, which shows the frequency of different categories of stakeholders that were identified as significant in the adapted PIPA exercises at the inception workshop).
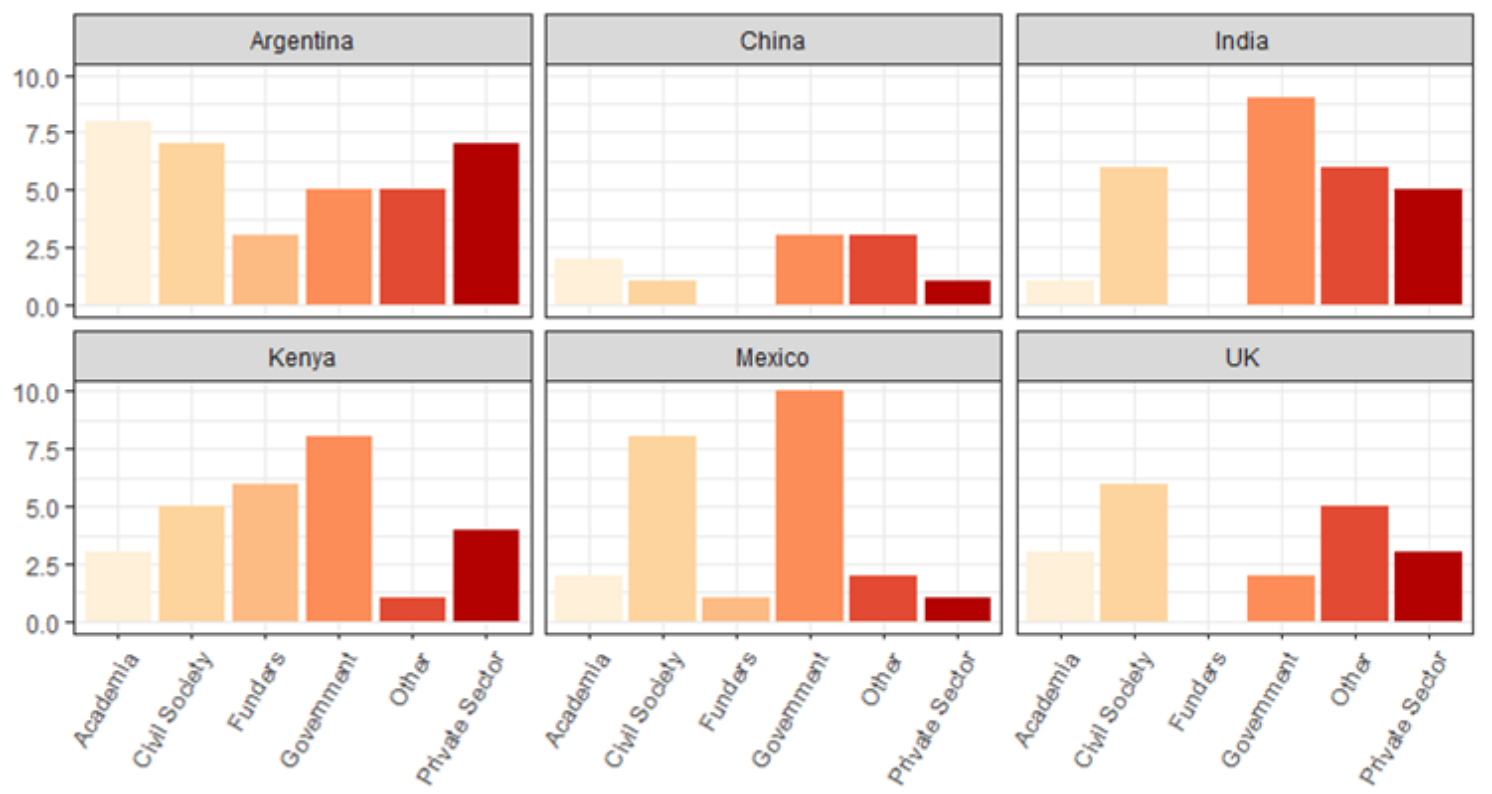

Figure 1. Number of stakeholders of each category identified as significant in the adapted Participatory Impact Pathways Analysis (PIPA) process carried out by each hub at the inception workshop.

These illustrate the perceptions of team members of each hub at the outset of the project about which stakeholders would need to be engaged in the process. However, differences in the ways in which the various T-Labs evolved meant that continued longitudinal analysis (drawing on stakeholder participation data in reports from the first and second workshops to compare how stakeholder engagement developed through time) was seen as inappropriate by some hubs. At the same time, an evaluation of the TKN at the final workshop in 2018 identified the flexibility that had been afforded to each of the hubs as one of the most positive aspects of the project (see Table 5). 
Table 5. Summary of positive and negative aspects of TKN collected from evaluation at final workshop (involving junior and senior representatives from all hubs).

\begin{tabular}{|c|c|}
\hline What Worked? & What Didn't Work? \\
\hline Respect, learning from diversity across hubs & $\begin{array}{l}\text { Time and resources were a constraint to interactions, } \\
\text { reflection and learning }\end{array}$ \\
\hline $\begin{array}{l}\text { Inception workshop for getting to know each other } \\
\text { made a good base- the culture and tone of the project } \\
\text { set from the start }\end{array}$ & $\begin{array}{c}\text { Theoretical and methodological exchanges were } \\
\text { limited (different hubs approached methods very } \\
\text { differently) }\end{array}$ \\
\hline Friendships and networking & $\begin{array}{l}\text { Technological challenges of virtual, de-centralised } \\
\text { information exchange: all platforms problematic or } \\
\text { limited }\end{array}$ \\
\hline $\begin{array}{l}\text { Autonomy in the hubs was appreciated (freedom to } \\
\text { find what works for them) }\end{array}$ & $\begin{array}{l}\text { Opportunities for follow-on funding have not been } \\
\text { successful }\end{array}$ \\
\hline $\begin{array}{l}\text { Knowledge generation and the move from their } \\
\text { research to action and impact }\end{array}$ & South-South interactions were not fully made use of \\
\hline $\begin{array}{l}\text { Having meetings at points throughout the project } \\
\text { was great } \\
\text { Establishing global movement in sustainability, } \\
\text { transformative research and action }\end{array}$ & $\begin{array}{c}\text { Pairing hubs didn't always work due to different } \\
\text { approaches/lack of continuity of } \\
\text { engagement/'chemistry' }\end{array}$ \\
\hline $\begin{array}{l}\text { Legitimate input from the global South } \\
\text { Connecting the community beyond the limits of their } \\
\text { own territories to bring in new learning }\end{array}$ & $\begin{array}{l}\text { Stakeholders in hubs expect continued support but } \\
\text { resources are no longer available }\end{array}$ \\
\hline $\begin{array}{l}\text { Central synthesising of information was helpful to } \\
\text { internal communications } \\
\text { Commitment from hubs despite challenges faced in } \\
\text { their different contexts of work }\end{array}$ & $\begin{array}{c}\text { Measuring impact because of a lack of clear definition } \\
\text { of what impact is }\end{array}$ \\
\hline
\end{tabular}

Exchanges, shared surveys, design formats and reports all contributed to mutual learning across the hubs, as testified to by the co-learning blogs and multi-hub-authored papers that have emerged from the project. Whilst bi-monthly teleconferences (involving individuals across up to sixteen time zones) were valuable enough to be continued one year after the project officially ceased, the use of virtual platforms (Microsoft Sharepoint, selected largely because of problems using Google in China and preferences for different platforms across geographies and generations for example, Slack/Zoom/Skype) was seen as a weakness to be improved in future work. More resources and time for collective reflection and better platforms for remote exchange of experiences, ideas and insights, may also have yielded more general overarching theories of transformation or of how to learn together better. However, this is by no means guaranteed.

\subsection{Transformation, Emergence and Evaluation}

Externally funded transdisciplinary research that seeks to open up opportunities for transformative change must move with the real life processes of co-production, reframing and ultimately unpredictable processes of emergent change with stakeholders. The TKN managed this explicitly through the combination of design structures and 'anchors' that were contextualised in each hub to produce the rich diversity of experiences shared here and in other learning outputs. This reflexive double loop learning approach, however, poses challenges to linear models of evaluation and learning that tend to require predefined indicators of outcomes (Table 5 claimed that "measuring impact because of a lack of clear definition of what impact is" was a problem). As a result, normative, change-seeking participatory research engagements often struggle to evaluate their contribution to change-and as a result the evidence based on how they work remains limited.

There is now a new suite of complexity-aware approaches to evaluation most prevalent in the development sector (e.g., [68-72]) that employ reflexive use of theory of change as both a process and a 
product. In contrast to a linear view of change and measurement approach to impact, the approach argues for a combination of inductive and deductive reasoning - through reflecting on underlying assumptions about how change happens that have been made explicit at the outset (double loop learning) - it is possible to build middle range theory of how change happens, as it happens. We begin to see now a new trend of this application of theory of change also within the sustainability science domain (e.g., [73,74]). The experience of the TKN provides instructive learning on the opportunities and challenges we face as we navigate the tension between a linear view of project management and evaluation that is aimed mainly at accountability and the need for more complexity-aware approaches that can help us understand how transdisciplinarity enables real impact.

The use of PIPA by the TKN was an important starting point for identifying potential opportunities for creating change (prospective use of theory of change at design phase). Further, explicit discussions on the underlying theories of transformation (see Table 3) provided additional insights into how the hubs hypothesized the T-Labs could support change (prospective definition of a theory of action). But returning to these periodically to identify evidence and make causal inference around how change was unfolding as a result of the T-Lab interventions, was challenging for multiple reasons (see Table 5): (i) the project timeframe meant observable evidence of change was necessarily limited; (ii) staying focused on the action orientation of the work can make stopping and reflecting on what is being achieved difficult; and (iii) evidencing a causal claim requires that there is sufficient clarity of what the hypothesized link is between a cause and an effect and this requires that theories of change are developed with the right level of detail.

It is only now, as the TKN collectively reflects (and continues to generate evidence) and now that pathways of change are becoming more apparent, that such a retrospective evaluation opportunity becomes possible, however time and resources (a year after the project's official completion) are a constraint. The key learning here is that funders and implementers alike should provide the space and resourcing required to enable reflexive use of theory of change to support evaluation research alongside implementation. Whilst this time was built into the Pathways TKN design (see Table 2), more was evidently needed.

\section{Discussion and Conclusions}

The findings above point to a number of insights emerging from the structured approach to collaboration adopted in the 'Pathways' transformative knowledge network. The project investigated how pathways to sustainability can be understood and nurtured through transdisciplinary research in different contexts and sought to foster "learning across disciplines, cultures and contexts". The paper shows that progress has been made in both of these difficult areas (with relatively modest time and financial resources) and provides a foundation upon which future generations of projects can build. The structured approach to collaboration provided an effective way of balancing the desire for a coherent, international project with the need for deep context-specificity. The use of theoretical and methodological anchors that provided the flexibility for transdisciplinary work in each hub to be locally co-designed and implemented was valued by the project team whilst still offering opportunities to compare across hubs. This enabled some learning across disciplines, cultures and contexts, highlighting similarities and differences in the epistemological frameworks (Table 3), methodological approaches (Table 4 ) and normative commitments in different hubs. The opportunity for "framed creativity" $[75,76]$ within the different contexts provided insights both in terms of single-loop (learning through theoretically-informed action, in this case enabling individual hubs to adopt more effective research and engagement methods in the future); and double-loop learning (questioning the values underlying theories in order to improve them, in this case via negotiation and reflection alongside teams from other hubs in the network). In each hub, these experiences will inform future transdisciplinary work that brings research and action together to address sustainability challenges.

The ambition for 'triple loop learning' (learning about the learning process, with the hope of learning how to learn better) bore fruit to the extent that key findings were identified in related 
work on transformative spaces [66], re-framing $[37,67]$ and alignment and power in transdisciplinary engagement [22] and to some extent around theoretical/methodological anchors, learning and evaluation (in this paper). Each of these offer possible foci for future work, either in the same sites (building on insights to date) or in novel contexts. Members of the transformative knowledge network continue to seek opportunities for follow-on projects that can employ, test and further enhance this learning.

The identification of other positive and negative elements of the project (elucidated at the final project workshop in 2018-see Table 5) offer a wealth of knowledge about how similar networked collaborations might be designed and implemented better in the future. The apparently contradictory evaluations also illustrate how notions of 'better' themselves differ from the perspectives of different institutionally-embedded research teams or individuals.

The need for deep appreciation of the different scholarly (and activist) traditions in the different regions of the network was identified as requiring more time than was available from the current project. Even so, a culture of respect and learning from diversity across the hubs was established at the outset and provided a foundation for this cross-cultural understanding. Exchanges and regular meetings were useful in this regard and 'co-learning blogs' provided opportunities to reflect.

Each of the hubs have published articles about their activities and there have been a number of cross-hub publications (including one other with inputs from all hubs [48]). But whilst these may be valued by the academic community and the institutions in which the authors are embedded, they do not reflect the overarching motivations or achievements of the TKN. As outlined above and in other work on transdisciplinary action research towards sustainability [11], these activities often provide little in the way of "scientific" impact. This raises the question of whether new/different types of criteria should be adopted to evaluate the effectiveness of scientific projects such as these, where enhancing mutual understanding and learning and contributing to transformative change are prioritized over codifying specific contributions to formal scientific knowledge.

Articulating an overarching theory of transformation, theory of change or even "best" practice (in terms of transdisciplinary engagement) proved challenging due to diversity across the network, as well as limitations of face-to-face and online opportunities for reflection and exchange However, the absence of an overarching and universally-adopted theory from the TKN should not necessarily be seen as a failure. Indeed, it could be seen as overly hubristic (or academically imperialist) to expect the emergence of a theory of transdisciplinary collaboration that applies across all disciplines, cultures and contexts. Rather, this paper offers a number of lessons for future international transdisciplinary collaborations that address locally-specific sustainability challenges against the backdrop of a shared global agenda (such as the universal framework of the SDGs). These could be further examined in future structured collaborations that apply some of the lessons learned from the 'Pathways' TKN to new cases or build upon the rich body of knowledge that has emerged from the network so far.

Author Contributions: A.E.: conceptualization, project co-lead, original draft preparation; A.M.: project co-lead; L.C.-J.: theory and methods research (coordinating Tables 3 and 4); P.O. \& L.P.: T-Labs; A.E., A.M., L.C.-J., D.A., M.A., J.A., R.A., R.B., B.K.C., V.C., A.C., R.D., P.D., H.E., P.K., F.M., K.M., N.N., C.O., D.O., P.O., N.O., L.P., R.P., A.T., P.V.Z., L.Y.: investigation, writing, review and editing. All authors have read and agreed to the published version of the manuscript.

Funding: This research was funded by the Transformations to Sustainability (T2S) Programme, which was coordinated by the International Science Council (ISC) and funded by the Swedish International Development Cooperation Agency (Sida) and implemented in partnership with the National Research Foundation of South Africa (Grant Number ISSC2015-TKN150224114426); and the UK Economic and Social Research Council (ESRC) STEPS Centre, grant number RES-588-28-0001.

Acknowledgments: The authors acknowledge the early inputs of Melissa Leach, Ian Scoones and Andy Stirling into the conception and design of the project and to thank Ed Hackett for his advice and support. Beyond that, they wish to thank the innumerable inputs and contributions of those colleagues and partners who were involved in project activities and T-Labs in each of the hubs.

Conflicts of Interest: The authors declare no conflict of interest. The funders had no role in the design of the study; in the collection, analyses or interpretation of data; in the writing of the manuscript or in the decision to publish the results. 


\section{References}

1. United Nations General Assembly (UNGA). Transforming our World: The 2030 Agenda for Sustainable Development; United Nations General Assembly: New York, NY, USA, 2015.

2. UNGSDR. United Nations Global Sustainable Development Report 2019: The Future Is Now-Science for Achieving Sustainable Development; United Nations: New York, NY, USA, 2019.

3. Future Earth. Future Earth Annual Report 2018-2019. Available online: https://futureearth.org/publications/ annual-reports/ (accessed on 15 March 2020).

4. Ely, A.; Marin, A. Learning about 'Engaged Excellence' across a Transformative Knowledge Network. IDS Bull. 2017, 47, 73-86. [CrossRef]

5. National Research Council. Facilitating Interdisciplinary Research; National Academies Press: Washington, DC, USA, 2005.

6. Clark, W.C. Sustainability Science: An Emerging Interdisciplinary Frontier; The Rachel Carson Distinguished Lecture Series; Michigan State University: East Lansing, MI, USA, 2007.

7. Hirsch Hadorn, G.H.; Pohl, C. Principles for Designing Transdisciplinary Research; Oekom Verlag: Munich, Germany, 2007.

8. Hirsch Hadorn, G.H.; Hoffmann-Riem, H.; Biber-Klemm, S.; Grossenbacher-Mansuy, W.; Joye, D.; Pohl, C.; Wiesmann, U.; Zemp, E. (Eds.) Handbook of Transdisciplinary Research. Proposed by the Swiss Academies of Arts and Sciences; Springer: Berlin/Heidelberg, Germany, 2008.

9. Hackmann, H.; St Clair, A.L. Transformative Cornerstones of Social Science Research for Global Change Report of the International Social Science Council; International Social Science Council: Paris, France, 2012.

10. Mauser, W.; Klepper, G.; Rice, M.; Schmalzbauer, B.S.; Hackmann, H.; Leemans, R.; Moore, H. Transdisciplinary global change research: The co-creation of knowledge for sustainability. Curr. Opin. Environ. Sust. 2013, 5, 420-431. [CrossRef]

11. Brandt, P.; Ernst, A.; Gralla, F.; Luederitz, C.; Lang, D.J.; Newig, J.; Reinert, F.; Abson, D.J.; von Wehrden, H.A. Review of transdisciplinary research in sustainability science. Ecol. Econ. 2013, 92, 1-15. [CrossRef]

12. Thompson Klein, J. Sustainability and Collaboration: Crossdisciplinary and Cross-Sector Horizons. Sustainability 2020, 12, 1515. [CrossRef]

13. Norström, A.V.; Cvitanovic, C.; Löf, M.F.; West, S.; Wyborn, C.; Balvanera, P.; Bednarek, A.T.; Bennett, E.M.; Biggs, R.; De Bremond, A.; et al. Principles for knowledge co-production in sustainability research. Nat. Sustain. 2020, 3, 182-190. [CrossRef]

14. Miller, C.A.; Wyborn, C. Co-production in global sustainability: Histories and theories. Environ. Sci. Policy 2018. corrected proof published online. [CrossRef]

15. Future Earth. Future Earth 2025 Vision; International Council for Science (ICSU): Paris, France, 2014.

16. Ostrom, E. Scales, polycentricity and incentives: Designing complexity to govern complexity. In Protection of Global Biodiversity: Converging Strategies; Guruswamy, L.D., McNeely, J.A., Eds.; Duke University Press: Raleigh, NC, USA, 1998; pp. 46-66.

17. Jasanoff, S. (Ed.) States of Knowledge: The Co-Production of Science and Social Order; Routledge: London, UK, 2004.

18. Russell, A.W.; Wickson, F.; Carew, A.L. Transdisciplinary: Context, contradictions and capacity. Futures 2008, 40,460-472. [CrossRef]

19. Arora, S. Admitting uncertainty, transforming engagement: Towards caring practices for sustainability beyond climate change. Reg. Environ. Chang. 2019, 19, 1571-1584. [CrossRef]

20. Pathways Network. T-Labs: A Practical Guide-Using Transformation Labs (T-Labs) for Innovation in Social-Ecological Systems; STEPS Centre: Brighton, UK, 2018.

21. Schäpke, N.; Stelzer, F.; Caniglia, G.; Bergmann, M.; Wanner, M.; Singer-Brodowski, M.; Loorbach, D.; Olsson, P.; Baedeker, C.; Lang, D.J. Jointly experimenting for transformation? Shaping real-world laboratories by comparing them. GAIA 2018, 27, 85-96. [CrossRef]

22. Marin, A.; Ely, A.; van Zwanenberg, P. Co-design with aligned and non-aligned knowledge partners: Implications for research and coproduction of sustainable food systems. Curr. Opin. Environ. Sust. 2016, 20, 93-98. [CrossRef]

23. Argyris, C.; Schön, D.A. Organizational Learning II: Theory, Method and Practice; Addison-Wesley: Redwood City, CA, USA, 1996. 
24. Van Zwanenberg, P.; Marin, A.; Ely, A. How Do We End the Dominance of Rich Countries Over Sustainability Science? STEPS Centre: Brighton, UK, 2016.

25. Star, S.L.; Griesemer, J.R. Institutional Ecology, 'Translations' and Boundary Objects: Amateurs and Professionals in Berkeley's Museum of Vertebrate Zoology, 1907-1939. Soc. Stud. Sci. 1989, 19, 387-420. [CrossRef]

26. Van Zwanenberg, P.; Ely, A.; Smith, A. Regulating Technology: International Harmonization and Local Realities; Routledge: Abingdon, UK, 2011.

27. Fressoli, M.; Arond, E.; Dinesh Abrol, D.; Smith, A.; Ely, A.; Dias, R. When grassroots innovation movements encounter mainstream institutions: Implications for models of inclusive innovation. Innov. Dev. 2014, 4, 277-292. [CrossRef]

28. Leach, M. (Ed.) Re-framing Resilience: A Symposium Report: STEPS Working Paper 13; STEPS Centre: Brighton, UK, 2008.

29. STEPS Centre. Innovation, Sustainability, Development: A New Manifesto; STEPS Centre: Brighton, UK, 2010.

30. Leach, M.; Rockström, J.; Raskin, P.; Scoones, I.; Stirling, A.C.; Smith, A.; Thompson, J.; Millstone, E.; Ely, A.; Arond, E.; et al. Transforming innovation for sustainability. Ecol. Soc. 2012, 17, 1708-3087. [CrossRef]

31. Leach, M.; Scoones, I.; Stirling, A.C. Dynamic Sustainabilities: Technology, Environment and Social Justice; Routledge/Earthscan: Abingdon, UK, 2010.

32. Goffman, E. Frame Analysis: An Essay on the Organization of Experience; Northeastern University Press: Boston, MA, USA, 1974.

33. Schön, D.; Rein, M. Frame Reflection: Towards the Resolution of Intractable Policy Issues; Basic Books: New York, NY, USA, 1994.

34. Levidow, L.; Murphy, J. Reframing regulatory science: Trans-Atlantic conflicts over GM crops. Cahiers D'économie et Sociologie Rurales 2003, 68-69, 48-74.

35. Ely, A.; Stirling, A.; Wendler, F.; Vos, E. The process of framing. In Food Safety Governance: Integrating Science, Precaution and Public Involvement; Dreyer, M., Renn, O., Eds.; Springer: Berlin/Heidelberg, Germany, 2009; pp. 47-56.

36. Cavicchi, B.; Ely, A. Framing and Reframing Sustainable Bioenergy Pathways: The Case of Emilia Romagna: STEPS Working Paper 88; STEPS Centre: Brighton, UK, 2016.

37. Marshall, F.; Randhawa, P.; Kushwaha, P.; Desai, P. Pathways for sustainable urban waste management and reduced environmental health risks in India: Winners, losers and alternatives to Waste to Energy in Delhi. Front. Sustain. Cities. (under review).

38. Westley, F.; Olsson, P.; Folke, C.; Homer-Dixon, T.; Vredenburg, H.; Loorbach, D.; Thompson, J.; Nilsson, M.; Lambin, E.; Sendzimir, J.; et al. Tipping toward sustainability: Emerging pathways of transformation. AMBIO 2011, 40, 762-780. [CrossRef]

39. Schot, J.; Kivimaa, P.; Torrens, J. Transforming Experimentation: Experimental Policy Engagements and Their Transformative Outcomes; Transformative Innovation Policy Consortium: Brighton, UK, 2019; Available online: https://www.tipconsortium.net/wp-content/uploads/2019/07/Transforming-Experimentation.pdf (accessed on 15 March 2020).

40. Nevens, F.; Frantzeskaki, N.; Gorissen, L.; Loorbach, D. Urban transition labs: Co-creating transformative action for sustainable cities. J. Clean. Prod. 2013, 50,111-122. [CrossRef]

41. Hassan, Z. The Social Labs Revolution; Berrett-Koehler Publisher: Oakland, CA, USA, 2014.

42. Westley, F.; Laban, S. (Eds.) Social Innovation Lab Guide; Waterloo Institute for Social Innovation and Resilience: Waterloo, ON, Canada, 2015.

43. Bergvall-Kåreborn, B.; Ståhlbröst, A. Living lab: An open and citizen centric approach for innovation. IJIRD 2009, 1, 356-370. [CrossRef]

44. Keyson, D.V.; Guerra-Santin, O.; Lockton, D. (Eds.) Living Labs: Design and Assessment of Sustainable Living; Springer International Publishing: New York, NY, USA, 2017.

45. Wagner, F.; Schäpke, N.; Stelzer, F.; Bergmann, M.; Lang, D.J. BaWü-labs on their way: Progress of real-world laboratories in Baden-Württemberg. GAIA 2016, 25, 220-221. [CrossRef]

46. Douthwaite, B.; Alvarez, S.; Cook, S.; Davies, R.; George, P.; Howell, J.; MacKay, R.; Rubiano, J. Participatory impact pathways analysis: A practical application of program theory in research for development. Can. J. Program Eval. 2007, 22, 127-159. 
47. Ely, A.; Oxley, N. STEPS Centre Research: Our Approach to Impact, STEPS Working Paper 60; STEPS Centre: Brighton, UK, 2014.

48. Scoones, I.; Stirling, A.; Abrol, D.; Atela, J.; Charli-Joseph, L.; Eakin, H.; Ely, A.; Olsson, P.; Pereira, L.; Priya, R.; et al. Transformations to Sustainability: STEPS Working Paper 104; STEPS Centre: Brighton, UK, 2018.

49. Abson, D.J.; Fischer, J.; Leventon, J.; Newig, J.; Schomerus, T.; Vilsmaier, U.; von Wehrden, H.; Abernethy, P.; Ives, C.D.; Jager, N.W.; et al. Leverage points for sustainability transformation. AMBIO 2017, 46, 30-39. [CrossRef] [PubMed]

50. O’Brien, K. Global environmental change II: From adaptation to deliberate transformation. Prog. Hum, Geogr. 2012, 36, 667-676. [CrossRef]

51. Olsson, P.; Galaz, V.; Boonstra, W.J. Sustainability transformations: A resilience perspective. Ecol. Soc. 2014, 19, 1. [CrossRef]

52. Pelling, M. Transformation: A renewed window on development responsibility for risk management. $J$. Extrem. Events 2014, 1, 1402003. [CrossRef]

53. Pelling, M.; O’Brien, K.; Matyas, D. Adaptation and transformation. Clim. Chang. 2015, 133, $113-127$. [CrossRef]

54. Westley, F.R.; Tjornbo, O.; Schultz, L.; Olsson, P.; Folke, C.; Crona, B.; Bodin, Ö. A theory of transformative agency in linked social-ecological systems. Ecol. Soc. 2013, 18, 27. [CrossRef]

55. Wise, R.M.; Fazey, I.; Smith, M.S.; Park, S.E.; Eakin, H.C.; Van Garderen, E.A.; Campbell, B. Reconceptualising adaptation to climate change as part of pathways of change and response. Glob. Environ. Chang. 2014, 28, 325-336. [CrossRef]

56. Haasnoot, M.; Kwakkel, J.H.; Walker, W.E.; ter Maat, J. Dynamic adaptive policy pathways: A method for crafting robust decisions for a deeply uncertain world. Glob. Environ. Chang. 2013, 23, 485-498. [CrossRef]

57. Scoones, I.; Leach, M.; Newell, P. (Eds.) The Politics of Green Transformations; Routledge: Abingdon, UK, 2015.

58. Smith, A.; Stirling, A.; Berkhout, F. The governance of sustainable socio-technical transitions. Res. Policy 2005, 34, 1491-1510. [CrossRef]

59. Geels, F.; Schot, J. Typology of sociotechnical transition pathways. Res. Policy 2007, 36, 399-417. [CrossRef]

60. Elzen, B.; Geels, F.W.; Green, K. (Eds.) System Innovation and the Transition to Sustainability: Theory, Evidence and Policy; Edward Elgar: Cheltenham, UK, 2008.

61. Ockwell, D.; Atela, J.; Mbeva, K.; Chengo, V.; Byrne, R.; Durrant, R.; Kasprowicz, V.; Ely, A. Can pay-as-you-go, digitally enabled business models support sustainability transformations in developing countries? Outstanding questions and a theoretical basis for future research. Sustainability 2019, 11, 2105. [CrossRef]

62. Chulin, J.; Yang, L.; Jian, X.; Ely, A. Research on 'Green Unemployed Group’ from the perspective of resilience. Guizhou Soc. Sci. 2018, 347, 135-142.

63. Tyfield, D.; Ely, A.; Geall, S. Low carbon innovation in China: From overlooked opportunities and challenges to transitions in power relations and practices. Sustain. Dev. 2015, 23, 206-216. [CrossRef]

64. Schmitz, H. Who drives climate-relevant policies in the rising powers? New Political Econ. 2017, 22, 521-540. [CrossRef]

65. Pereira, L.M.; Karpouzoglou, T.; Frantzeskaki, N.; Olsson, P. Designing transformative spaces for sustainability in social-ecological systems. Ecol. Soc. 2018, 23, 32. [CrossRef]

66. Pereira, L.M.; Frantzeskaki, N.; Hebinck, A.; Charli-Joseph, L.; Drimie, S.; Dyer, M.; Eakin, H.; Galafassi, D.; Karpouzoglou, T.; Marshall, F.; et al. Transformative spaces in the making: Key lessons from nine cases in the Global South. Sustain. Sci. 2019, 15, 161-178. [CrossRef]

67. Marshall, F.; Van Zwanenberg, P.; Charli-Joseph, L.; Ely, A.; Eakin, H.; Marin, A.; Priya, R. Chapter 8: Reframing sustainability challenges. In Transformative Pathways to Sustainability: Learning Across Disciplines, Cultures and Contexts; Ely, A., Ed.; Routledge: Abingdon, UK, 2020.

68. Douthwaite, B.; Apgar, J.M.; Schwarz, A.-M.; Attwood, S.; Sellamuttu, S.S.; Clayton, T. A new professionalism for agricultural research for development. Int. J. Agric. Sustain. 2017, 15, 1-15. [CrossRef]

69. Britt, H.; Patsalides, M. Complexity-Aware Monitoring. Discussion Note, Monitoring and Evaluation Series; USAID: Washington, DC, USA, 2013.

70. Patton, M.Q. Developmental Evaluation: Applying Complexity Concepts to Enhance Innovation and Use; Guilford Press: New York, NY, USA, 2010.

71. Vogel, I. Review of the Use of Theory of Change in International Development; DFID: London, UK, 2012. 
72. Moore, M.L.; Olsson, P.; Nilsson, W.; Rose, L.; Westley, F.R. Navigating emergence and system reflexivity as key transformative capacities. Ecol. Soc. 2018, 23, 38. [CrossRef]

73. Oberlack, C.; Breu, T.; Giger, M.; Harari, N.; Herweg, K.; Mathez-Stiefel, S.-L.; Messerli, P.; Moser, S.; Ott, C.; Providoli, I.; et al. Theories of change in sustainability science: Understanding how change happens. GAIA-Ecol. Perspect. Sci. Soc. 2019, 28, 106-111. [CrossRef]

74. Schneider, F.; Giger, M.; Harari, N.; Moser, S.; Oberlack, C.; Providoli, I.; Schmid, L.; Tribaldos, T.; Zimmermann, A. Transdisciplinary co-production of knowledge and sustainability transformations: Three generic mechanisms of impact generation. Environ. Sci. Policy 2019, 102, 26-35. [CrossRef]

75. Olsson, P.; Folke, C.; Berkes, F. Adaptive co-management for building resilience in social-ecological systems. Environ. Manag. 2004, 34, 75-90. [CrossRef] [PubMed]

76. Folke, C.; Hahn, T.; Olsson, P.; Norberg, J. Adaptive governance of social-ecological systems. Annu. Rev. Environ. Resour. 2005, 30, 441-473. [CrossRef]

(C) 2020 by the authors. Licensee MDPI, Basel, Switzerland. This article is an open access article distributed under the terms and conditions of the Creative Commons Attribution (CC BY) license (http://creativecommons.org/licenses/by/4.0/). 